\title{
Participação paterna na unidade de terapia intensiva neonatal segundo a concepção da equipe de enfermagem
}

\author{
Paternal participation in the neonatal \\ intensive care unit according to the \\ conception of nursing team
}

\section{Gustavo Assis Afonso ${ }^{1}$ (i) Nycolas Ferreira Xavier Francisco 2 (D) Rosane Belo Carvalho de Castro $^{3}$ (D)}

\footnotetext{
1'Autor para correspondência. Centro Universitário de Volta Redonda, (Rio de Janeiro), Rio de Janeiro, Brasil. guassis88@yahoo.com.br ${ }^{2-3}$ Centro Universitário de Volta Redonda, (Rio de Janeiro), Rio de Janeiro, Brasil. ferreiranycolas@yahoo.com.br, rosane.castro@foa.org.br
}

RESUMO | OBJETIVO: Identificar a visão de membros da equipe de enfermagem acerca da participação do pai durante a hospitalização do recém-nascido na unidade de terapia intensiva neonatal. MÉTODO: Abordagem exploratória de natureza qualitativa, por intermédio de um questionário aberto, e posteriormente, submetido à análise de conteúdo de Bardin. RESULTADOS: O exame das entrevistas levou à construção de três categorias: discrepância em reconhecer a singularidade do pai no trinômio pai-mãe-filho; o acolhimento e a inserção do pai no contexto de cuidados com o RN; criação do vínculo familiar e auxílio no desenvolvimento clínico do RN. CONCLUSÃO: A equipe de enfermagem reconhece a figura paterna como provedor de benefícios para o RN e implementa práticas que promovem o seu acolhimento e aproximação com o filho. Contudo, equipe ainda possui uma visão defasada sobre a verdadeira função da paternidade no contexto familiar, contribuindo para a criação de um estigma social do homem como coadjuvante.

DESCRITORES: UTI Neonatal. Equipe de Enfermagem. Pai.
ABSTRACT | OBJECTIVE: To identify the view adopted by the nursing team regarding the father's participation in the neonatal intensive care unit. METHOD: An exploratory approach of qualitative nature, through an open questionnaire, and eventually, submitted to Bardim's content analysis. RESULTS: The analysis of the survey led to the construction of 3 categories: A discrepancy in recognizing the singularity of the father in the father-mother-child trinomial; the reception and insertion of the father in the context of NICU care with the newborn; creation of family bond and assistance in the clinical development of the NB. CONCLUSION: Nursing recognizes the father figure as a provider of benefits to the NB and implements practices that promote their embracement and closeness with the child. However, the team still has a lagged view on the true role of fatherhood in the family context, contributing to the creation of a social stigma of men as an adjunct.

DESCRIPTORS: Neonatal ICU. Nursing Team. Father. 


\section{Introdução}

A Unidade de Terapia Intensiva Neonatal (UTIN) é o espaço de um nosocômio destinado aos cuidados de alta complexidade de crianças em estado de vida grave. Este ambiente deve ser composto de tecnologia moderna e profissionais qualificados no setor, a fim de garantir a assistência específica e avançada para reabilitação do cliente enfermo. ${ }^{1}$

Somado a isso, é fundamental para o desenvolvimento neuropsicomotor do recém-nascido (RN) que a UTIN deve ser planejada e organizada. A estrutura da unidade precisa garantir que todos os serviços prestados, sejam estes técnicos e assistenciais, atendam todas as necessidades do RN e sua família continuamente. ${ }^{?}$

Entretanto, mesmo com toda infraestrutura necessária para prestar a terapia intensiva, o processo de internação na UTIN pode oferecer riscos durante esse período para o desenvolvimento posterior na infância e na adolescência do RN. Procedimentos como: punção venosa, coleta de sangue, aspiração endotraqueal e de vias aéreas superiores, são alguns exemplos de atividades rotineiras no setor que podem desencadear traumas para o paciente..$^{3}$

Sendo assim, a família da criança hospitalizada também está submetida a um período de experiências no qual pode gerar traumas, ansiedade, medo, insegurança e outras repercussões negativas em suas vidas. Neste sentido, é imprescindível que o cuidado seja transversal para minimizar os impactos de uma internação. ${ }^{4}$

É possível explicitar o contexto em que a figura paterna reconhece as desigualdades no tratamento e funções atribuídas pela equipe de enfermagem, comparado com as participações das mães no cuidado dos recém-nascidos. Ainda é ressaltado que a mãe é vista como a protagonista no processo do cuidar da criança e o pai possui papel coadjuvante, ou seja, aquele menos importante e com tarefas auxiliadoras. $\underline{5}$

Cabe aos membros da equipe de enfermagem não somente prestar assistência voltada à criança, mas acolher o pai no âmbito hospitalar, a fim de promover a integralidade do atendimento e auxiliar esse familiar que muitas das vezes passa por sentimento de impotência, insegurança e incapacidade, geralmente colocado pela limitação e exclusão social.
Dessa forma, a visão social sobre a paternidade integral está fundamentada em construções de estereótipos e estigmas sociais transmitidos ao longo dos anos culturalmente, na qual a figura materna se destaca com protagonismo e que reflete em uma limitação da exerção paternal.

A atenção às necessidades do pai pode estar comprometida devido à maior dedicação e interesse dos profissionais voltada para o aperfeiçoamento de procedimentos, uma vez em que a destreza em realizar técnicas são mais valorizadas como características de uma boa equipe, colocando em segundo plano a intervenção com familiares e acompanhantes. $\underline{\underline{6}}$

Logo, a equipe de enfermagem está sujeita a um defasado modelo de tratamento biologista imposto nas rotinas de tratamento da terapia intensiva, na qual se abstraem questões relativas ao acolhimento e valorização dos sentimentos do pai no processo de hospitalização.

De acordo com a Portaria n. 930/2012 do Ministério da Saúde, o pai deve ser incentivado nos cuidados prestados ao RN na UTIN, além de ter livre acesso

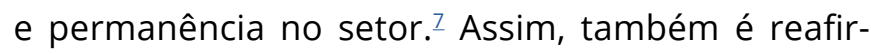
mada sua imprescindível participação no contexto da corresponsabilização do cuidado familiar através do Programa Nacional de Humanização como um agente individual necessário para compor os cuidados neonatais. ${ }^{.}$

Portanto, a equipe de enfermagem deve estar atenta em dirigir sua atenção ao pai durante todo o momento em que ele estiver presente no setor, a fim de sanar dúvidas, acolher e explicar a respeito dos recursos tecnológicos utilizados na assistência ao RN. $\stackrel{?}{ }$

É possível perceber a vontade do pai em interagir com a criança, mas sua insegurança e falta de oportunidade impedem a ação de participar no processo do cuidado. $\underline{6}$ Logo, a enfermagem deve realizar ações que estimulem o toque terapêutico para fortalecer o vínculo afetivo e promover a segurança do pai em exercer sua paternidade.

Dessa maneira, os pais devem ser envolvidos nos cuidados básicos, desde as primeiras visitas até o preparo da alta, como trocar fraldas, gavagem da dieta oferecida e higiene corporal.? 
Torna-se relevante, portanto, a necessidade de um estudo com o objetivo de identificar a visão de membros da equipe de enfermagem acerca da participação do pai durante a hospitalização do RN na UTIN.

Espera-se contribuir para uma reflexão e pensamento crítico dos profissionais de enfermagem acerca da presença paterna na UTIN e desenvolver condutas para a inclusão efetiva desse componente no contexto familiar; para o exercício do princípio de integralidade do Sistema Único de Saúde (SUS) no âmbito hospitalar, garantindo ações que fortaleçam políticas públicas efetivas de saúde; para a comunidade acadêmica no enriquecimento de conteúdo técnico-científico do tema proposto, haja vista a escassez encontrada sobre o assunto que aborda a visão paterna na UTIN, além de despertar interesse para futuros discentes acerca da importância do tema proposto; para a sociedade com a enfatização do modelo de construção social no qual entende a figura paterna como um protagonista no processo de cuidar da criança, extrapolando visões defasadas sobre o papel que o pai desempenha.

\section{Método}

O estudo se baseia em um método de abordagem exploratória e de natureza qualitativa.

Adotou-se como critério de inclusão a abordagem a todos os membros da equipe de enfermagem que aceitassem voluntariamente a contribuir para a pesquisa, sendo identificados os cargos de enfermeiros assistenciais, supervisores, coordenadores e técnicos de enfermagem com vínculo empregatício ativo no setor da UTIN. Não foi incluído no estudo aqueles que se encontravam afastados por atestado e licença médica, bem como aqueles que recusaram a participar da pesquisa. O convite de caráter voluntário foi realizado pelos autores da pesquisa para os profissionais de forma que contemplasse todas as escalas de jornada de trabalho.

Para isso, realizou-se a pesquisa em duas UTIN distintas no interior do Estado do Rio de Janeiro, no período de dezembro de 2019 a janeiro de 2020. A primeira pertence a uma instituição privada, com capacidade de 05 leitos de Unidade de Terapia Intensiva (UTI), 03 de Unidade de Cuidados Intermediários ( $\mathrm{UCI}$ ) e 02 leitos pediátricos, com possibilidade de atender 06 usuários do Sistema Único de Saúde (SUS). A unidade conta com uma equipe multiprofissional composta de 05 enfermeiros assistenciais e supervisores, sendo 04 sob regime de plantão de $24 \times 72 \mathrm{~h}$ e 01 com 8 horas diárias de trabalho, juntamente com 01 enfermeiro gestor da unidade, 13 técnicos de enfermagem com escala de plantão de $12 \times 36 \mathrm{~h}$. Oferece serviços de neonatologia, pediatria, fisioterapia, fonoaudiologia, psicologia, serviço social, nutrição, cardiologia, oftalmologia e ultrassonografia.

A segunda pertence a um hospital público, composta por 10 leitos de UTI, 5 leitos de UCI que não estão localizados dentro do setor, mas próximos, no corredor externo. A equipe possui 8 enfermeiros assistenciais e supervisores, sob regime de plantão de 24 horas por semana, 1 enfermeiro coordenador com 8 horas semanais de trabalho, 22 técnicos de enfermagem com o regime de trabalho de $24 \times 72 \mathrm{~h}, 5$ de $12 \times 60$ e 2 com 8 horas diárias de trabalho. Estão disponíveis os mesmos serviços multidisciplinares da primeira instituição.

Foi aplicado um questionário aberto composto por três questões norteadoras: "Quais os benefícios da presença do pai para o RN na UTIN? De que forma a equipe de enfermagem acolhe o pai no contexto da UTIN? Quais as estratégias adotadas pela equipe de enfermagem para incentivar a participação do pai durante a internação do recém-nascido na UTIN?". Os depoentes responderam em um local reservado no setor com privacidade, contemplando todos os horários de plantões diurnos, noturnos, ímpares e pares, incluindo os finais de semana. As entrevistas duraram em média 6 minutos para serem respondidas em ambas instituições. Todas foram transcritas integralmente para o computador pelos pesquisadores através do software Microsoft Word 2016.

Posteriormente, a coleta de dados foi submetida à análise de conteúdo de Bardin, divido em 3 etapas: a pré-análise, relacionado com a reunião e organização do material, realizando uma leitura flutuante deste; exploração do material, pelo método de codificação, classificação e categorização, com o objetivo de selecionar o conteúdo e dividi-lo por um processo sistemático; interpretação, associada com inferência do conteúdo levantado de acordo com a problemática explicitada na pesquisa..$^{10}$ 
A aplicação dos questionários aos participantes foi iniciada após a aprovação da submissão ao Comitê de Ética em Pesquisa Envolvendo Seres Humanos da Fundação Oswaldo Aranha (UNIFOA) conforme rege o item IV da Resolução n ${ }^{\circ} 466$ de 12 de dezembro de 2012, do Conselho Nacional de Saúde sob o parecer CAAE 24355919.4.0000.5237. Todos os convidados tiveram suas identidades preservadas a fim de garantir sua privacidade, sendo representados diferentemente pela letra inicial de cada classe - enfermeiro (E) e técnico de enfermagem $(T)$-, seguido posteriormente de uma numeração.

\section{Resultados e discussão}

Para a realização do estudo, participaram voluntariamente 10 enfermeiros e 28 técnicos de enfermagem, sendo todas pertencentes ao sexo feminino, com a média aproximada de idade de 38 e 41 anos, respectivamente. $O$ tempo de experiência profissional dos depoentes na UTIN corresponde a 31,42\% (11) menor ou igual a 1 ano; 17,14\% (6) entre 2 e 4 anos; $14,28 \%$ entre 5 e 9 anos; e 37,14\% (13) maior ou igual que 10 anos. Foram contabilizados 08 profissionais que se recusaram a responder as perguntas propostas.

Após reunião e processamento da coleta de dados dos questionários, foram identificadas 03 ideias centrais distintas que apresentam a participação do pai na UTIN através do depoimento da equipe de enfermagem: discrepância em reconhecer a singularidade do pai no trinômio pai-mãe-filho; o acolhimento e a inserção do pai no contexto de cuidados da UTIN; e o auxílio no desenvolvimento clínico do RN; e a criação do vínculo familiar e auxílio no desenvolvimento clínico do RN.

\section{(I) Discrepância em reconhecer a singularidade do pai no trinômio pai-mãe-filho:}

Durante os questionamentos voltados para a visão geral da equipe de enfermagem em relação ao pai, muitos membros responderam com a introdução da mãe no contexto, ressaltando sua presença sobre a figura paterna.
Infelizmente a equipe de enfermagem ainda não está com um olhar treinado para enxergar a família como um todo. O olhar ainda é muito restrito ao binômio mãe-filho, isentando o pai de uma participação mais efetiva no cuidado prestado ao RN internado. Devido a isso, muitos pais não conseguem perceber ou entender

a importância da sua presença, negligenciando, por vezes, de forma inconsciente, a sua colaboração na recuperação do recém-nascido. Poucas são as abordagens e incentivo da parte da enfermagem. (E.5)

O bebê se sente mais calmo com a presença familiar, não só a presença do pai, mas da mãe também. (E.7)

"Pedir que traga roupinhas (quando a mãe está impossibilitada de vir). (T.26)

As respostas explicitam a ideia de que os profissionais ainda não conseguem diferenciar a importância e a participação do pai no ambiente familiar.

Segundo a Lei $n^{\circ} 8.069$, de 13 de julho de 1990 do Instituto da Criança e do Adolescente (ECA), o pai e a mãe possuem os mesmos direitos, deveres e responsabilidades no que tange ao cuidado da criança. ${ }^{11}$

Além disso, de acordo com a teórica Wanda Horta, a enfermagem deve considerar o ser humano como autêntico, único e singular, pois está inserido em um universo onde busca manter o equilíbrio de suas funções. Caso ocorra o desequilíbrio, geram-se demandas que implicam em estados de tensão, sendo preciso atendê-las, já que estão relacionadas com as necessidades humanas básicas, as quais se relacionam com o nível social. ${ }^{12}$

Assim como as mães, os pais constituem um papel primordial no contexto familiar; contudo, ele possui demandas distintas da mulher, e é imprescindível que os profissionais de enfermagem estejam atentos ao tratamento dos pais a fim de incluí-lo no cenário da UTIN. Dessa forma, ao garantir atenção a sua participação, é possível promover a aplicabilidade de sua função social na família.

Ademais, as falas dos depoentes remetem à ideia cultural de que a figura paterna tem a função de auxiliar à mãe, exercendo função coadjuvante, enquanto ela está centralizada nos cuidados diretos para com o filho. ${ }^{13}$ 
Embora existam casos de internação onde a mãe esteja limitada nas visitas da UTIN, geralmente nos primeiros momentos do estágio puerperal, o pai se torna um elo de ligação entre ela e o RN, por ser aquele que tem os primeiros contatos com a criança e com a equipe de saúde. Porém, a equipe de enfermagem não deve considerar a participação do pai exclusivamente nesse contexto, mas, sim, em todos os momentos durante a hospitalização do RN.

Por conseguinte, isso contribui para a construção de um estigma social de um ser que possui função exclusiva de apoio, geralmente através da geração da renda familiar, o que inicia o afastamento da função integral da paternidade. ${ }^{14}$

Logo, ressalta-se que a presença paterna no ambiente da terapia intensiva neonatal é indispensável, haja vista que sua participação ultrapassa valores do senso comum e deve ser um objeto de atenção contínuo da equipe de enfermagem.

\section{(II) 0 acolhimento e a inserção do pai no contexto de cuidados com o RN}

Notou-se que alguns membros da equipe possuem a preocupação de acolher e introduzir o pai no contexto da rotina da UTIN, tornando-o um sujeito praticante do cuidar e com conhecimento sobre a situação clínica do RN.

A equipe de enfermagem deve acolher esse pai de uma forma mais humanizada, incentivando-o ao toque no bebê, a conversar, estimular o método canguru, esclarecendo todo processo de internação do bebê para que ele possa participar de uma forma mais ampla no cuidado e no tratamento de seu filho. As informações repassadas e toda dúvida esclarecida diminui a ansiedade do pai, assim, o mesmo fica mais calmo e passa segurança a seu filho. (E.7)

Acompanhar o desenvolvimento do filho hospitalizado, sabendo agir na hora das intercorrências quando este não estiver em ambiente hospitalar, deixar que os pais participem na hora da dieta desta criança, ensinando como ofertar a dieta por sucção, gavagem, troca da fralda, identificar possíveis assaduras, parte da higiene, mostrar como se é realizado, colocar fralda, roupa, aferir temperatura [...]. (T.8)
Orientando com instruções especificas do setor, acalmando sempre que for possível em momentos mais tensos. Tranquilizá-los quanto aos procedimentos rotineiros e o deixando à vontade para manifestar suas

dúvidas. (T.2)

O método canguru é evidenciado como uma das formas de inserção da paternagem nos cuidados diretos do RN, pois contribui para o aumento do ganho de peso, desenvolvimento cognitivo e motor, provêm calor necessário à manutenção da temperatura corporal, reduz risco de contrair infecções, diminui riscos de apneia e bradicardia, reduz o nível de estresse e dor, além de fortalecer o vínculo afetivo. $\frac{15}{}$

O acolhimento realizado com o pai permite o desempenho da paternidade, o que estabelece a aproximação com o filho na UTIN e o permite ser um agente do cuidado. Ao incentivá-lo a prestar assistência ao filho quando possível, inicia-se os primeiros processos de aprendizagem para que ele possa aprender sobre os cuidados com o RN.

Vale ressaltar que os homens apresentam sentimentos negativos de medo, insegurança, ansiedade e angústia quando se deparam com o filho internado, o que demanda de uma intervenção profissional. $\frac{16}{}$

Portanto, o preparo dos pais para visitarem o RN, atendimento singular, escuta qualificada, preocupação com os aspectos emocionais, inclusão do familiar na tomada de decisão acerca do plano de cuidados do $\mathrm{RN}$ e valorização das crenças são alguns fatores fundamentais atrelados à humanização para uma abordagem da enfermagem, extrapolando aspectos e condutas técnicas. ${ }^{17}$

Sendo assim, as estratégias que são desenvolvidas pelos profissionais no setor para acolher e aproximar o pai com a criança hospitalizada contribui significativamente para um acolhimento terapêutico. As atividades do acolhimento promovidas no ambiente de assistência à saúde geram benefícios para o cliente e seu familiar, gerando fatores que contribuem para o bem-estar dos entes envolvidos. 
Isso reflete em uma participação paterna mais efetiva no setor, uma vez que esses fatores irão promover vínculo de confiança não somente na equipe de enfermagem, como também em outros profissionais de saúde, permitindo que o pai possa expor suas dúvidas e sentimentos, tornando-o mais presente no ambiente da terapia intensiva.

Entretanto, percebeu-se relatos de que essa prática ainda se encontra dificultosa e distante de ser realizada integralmente em todo ambiente da terapia intensiva.

\section{Ainda temos poucas estratégias voltadas para inseri-lo} no contexto do cuidado. (E.5)

Pelo que vejo e vivo nessa unidade, é mínima a presença do pai na UTI, salvos alguns, que vêm e é nítido o bem-estar que faz ao bebê. (T.16)

Não tem muito incentivo, não. (T.17)

Um dos fatores que justificam a ausência da figura paterna na UTIN está pautado na legislação brasilei$\mathrm{ra}$, na qual a licença da paternidade se resume em apenas cinco dias. Esse curto período prejudica uma melhor interação do contato de pai-filho, haja vista que o ambiente da UTIN já causa separação familiar. $\frac{18}{}$

Somado a isso, as aparições do pai podem ocorrer, por vezes, em curto período de tempo, atrelada aos sentimentos de negatividade e afastamento, levando a não querer participar do vínculo durante a internação do RN. ${ }^{14}$

Isso se relaciona com a falta de acolhimento realizada com o homem durante as primeiras visitas ao filho hospitalizado, bem como a falta de acesso pelas demandas ocupacionais, o que contribuem para dúvidas, inseguranças de um ambiente desconhecido, culminando na falta de interesse de participar de todo o processo no setor. Dessa forma, observa-se o pai com múltiplas necessidades que carecem de atenção dos profissionais para um acoIhimento eficaz.

\section{(III) Criação do vínculo familiar e Auxílio no desenvolvimento clínico do RN}

Percebeu-se que os participantes reconhecem que a introdução do pai no contexto da UTIN favorece no estabelecimento do vínculo afetivo, no qual gera benefícios para a família, bem como na promoção do bem-estar clínico da criança.

A criança se sente em um ambiente mais familiar com a voz e o toque do pai, principalmente na troca de um vínculo pai-filho. (E.7)

O pai que acolhe o RN neste momento contribui com o vínculo deste bebê. (T.13)

Os benefícios maiores são os neurológicos, a criança se sente em um ambiente mais familiar com a voz e o toque do pai, principalmente na troca de um vínculo pai-filho. [...] diminui a FC (frequência cardíaca), ventilação, inúmeros benefícios podem ser notados.

O RN ganha peso mais rápido e tem uma recuperação melhor. (T.15)

Minimiza a dor e aconchega. (T.28)

A construção do vínculo familiar entre pai-filho inicia desde o período do pré-natal realizado juntamente com a mãe e se consolida a partir do nascimento da criança.19 Dessa forma, a paternidade continua seu desenvolvimento através de relações pessoais consigo e uma atuação gradativa de interação com o RN. 20

É importante que a equipe de enfermagem atue para alicerçar esse sentimento, pois a UTIN pode oferecer um risco a essa aproximação. A partir disso, é possível promover a função social do binômio pai e filho a partir dos primeiros momentos de contato entre estes dois seres.

Além disso, outros benefícios são evidenciados em estudos, principalmente relacionados ao método canguru, como o controle de temperatura corporal e níveis glicêmicos, melhora no padrão de sono, diminuição da ocorrência de choro, saturação de oxigênio, diminuição no risco de infecção e o tempo de internação hospitalar.21

A participação do pai, então, traz benefícios fisiológicos para o RN, promovendo uma melhora no desenvolvimento de seu estado geral.

Limitação do estudo: percebeu-se a problemática da dificuldade em responder o questionário por se tratar de um tema pouco discutido entre a equipe. 


\section{Conclusão}

Por ser afastado culturalmente de tarefas domésticas, o pai recebe um estigma social o qual o distancia de uma relação de cuidado mais íntimo com o filho, o que desvia a atenção de profissionais da saúde sobre sua consideração no contexto hospitalar. Torna-se evidente neste estudo, que a presença da figura paterna é indispensável no ambiente da UTIN.

Foi evidenciado na pesquisa que o pai promove o bem-estar para RN através do vínculo afetivo e contribui para a sua melhora clínica, entretanto, embora existam estratégias da enfermagem para aproximá-los, alguns profissionais relataram dificuldade em adotar essa prática, seja por deficiência do incentivo institucional ou pela ausência do pai.

Portanto, é fundamental que as práticas de educação continuada ganhem destaque nas estratégias dos gestores a fim de criar uma equipe de enfermagem mais acolhedora do pai, a fim de capacitar os trabaIhadores independendo do tempo de experiência profissional.

Exercer a paternidade se trata de um direito e dever do homem, desse modo, cabe à enfermagem reconhecer esse valor fundamental e desenvolver novos protocolos de aproximação entre pai e filho durante o processo de hospitalização na terapia intensiva, além de fazer valer as políticas públicas já existentes.

\section{Contribuições dos autores}

Afonso GA e Francisco NFX participaram da concepção, delineamento, busca e análise estatística dos dados da pesquisa, formulação dos métodos, aplicação dos questionários na pesquisa de campo, interpretação dos resultados, elaboração da discussão, conclusão e redação do artigo científico. Castro RBC participou da concepção, delineamento, busca e análise estatística dos dados da pesquisa, formulação dos métodos, da discussão e da redação do artigo científico.

\section{Conflito de interesses}

Nenhum conflito financeiro, legal ou político envolvendo terceiros (governo, empresas e fundações privadas, etc.) foi declarado para nenhum aspecto do trabalho submetido (incluindo, mas não se limitando a subvenções e financiamentos, participação em conselho consultivo, desenho de estudo, preparação de manuscrito, análise estatística, etc.).

\section{Referências}

1. Ribeiro JF, Silva LLC, Santos IL, Luz VLES, Coêlho DMM. O prematuro em unidade de terapia intensiva neonatal: a assistência do enfermeiro. Rev enferm UFPE On line [Internet]. 2016;10(10):3833-41. Disponível em: https://periodicos.ufpe.br/ revistas/revistaenfermagem/article/view/11450/13268

2. Tamez RN. Enfermagem na UTI neonatal: Assistência ao recémnascido de alto risco. 6a. ed. Rio de Janeiro: Guanabara Koogan; 2017.

3. Magalhães FJ, Lima FET, Rolim KMC, Cardoso MVLML, Sherlock MSM, Albuquerque NLS. Respostas fisiológicas e comportamentais de recém-nascidos durante o manuseio em unidade de terapia intensiva neonatal. Rev Rene. 2011;12(1):13643. Disponível em: http://periodicos.ufc.br/rene/article/view/4170

4. Azevedo AVS, Lançoni Junior AC, Crepaldi MA. Interação equipe de enfermagem, família, e criança hospitalizada: revisão integrativa. Ciênc saúde colet. 2017;22(11):3653-66. https://doi. org/10.1590/1413-812320172211.26362015

5. Monteiro FP, Rios MIM, Shimo AKK. A participação paterna em Unidades de Terapia Intensiva Neonatal. Rev ciênc méd. 2014;23(3):145-51. https://doi.org/10.24220/23180897v23n3a2825

6. Marski BSL, Custodio N, Abreu FCP, Melo DF, Wernet M. Alta hospitalar do recém-nascido prematuro: experiência do pai. Rev. Bras. Enferm. 2016;69(2):221-8. https://doi.org/10.1590/00347167.2016690203i

7. Portaria n 930, de 10 de maio de 2012 (Brasil). Define as diretrizes e objetivos para a organização da atenção integral e humanizada ao recém-nascido grave ou potencialmente grave e os critérios de classificação e habilitação de leitos de Unidade Neonatal noâmbito do Sistema Único de Saúde (SUS). [Internet]. Diário Oficial da União. 2012 mai 10. Disponível em: http://bvsms. saude.gov.br/bvs/saudelegis/gm/2012/prt0930 1005 2012.html

8. Ministério da Saúde (Brasil). HumanizaSUS. Política Nacional de Humanização da Saúde [Internet]. Brasília: Ministério da Saúde; 2013. Disponível em: http://bvsms.saude.gov.br/bvs/publicacoes/ politica_nacional_humanizacao_pnh_folheto.pdf

9. Carvalho JBL, Araújo ACPF, Costa ICC, Brito RS, Souza NL. Representação social de pais sobre o filho prematuro na unidade de terapia intensiva neonatal. Rev. bras. enferm [Internet]. 2009;62(5):734-8. Disponível em: https://pesquisa.bvsalud.org/ portal/resource/pt/lil-531573

10. Câmara RH. Análise de Conteúdo: da teoria à prática em pesquisas sociais aplicadas às organizações. Gerais: Rev Interinst Psicol [Internet]. 2013;6(2):179-91. Disponível em: http://pepsic.bvsalud.org/scielo.php?script=sci arttext\&pid=S1983-82202013000200003 
11. Lei 8.069, de 13 de julho de 1990 (Brasil). Dispõe sobre o Estatuto da Criança e Adolescente e dá outras providências. [Internet]. Diário Oficial da União. 1990 jul 13. Disponível em: http://www.planalto.gov.br/ccivil 03/leis//8069.htm

12. Horta WA. Enfermagem: teoria, conceitos, princípios e processo. Rev. esc. enferm. USP. 1974;8(1):7-17. https://doi. org/10.1590/0080-6234197400800100007

13. Borges KI, Santana JO, Souza DA, Silva VCE, Pinto KRTF, Zani $A V$. Vivências do pai/homem no cuidado ao filho prematuro hospitalizado. Rev Min Enferm. 2018;22:e-1141. http://www. dx.doi.org/10.5935/1415-2762.20180071

14. Carvalho E, Mafra PPOC, Schultz LF, Schumacher B, Aires LCPA. Inclusão e participação nos cuidados ao filho pré-termo na unidade neonatal: percepções paternas. Rev Enferm UFSM. 2019;9(31):1-19. https://doi.org/10.5902/2179769231121

15. Lopes TRG, Santos VEP, Carvalho JBL. A presença do pai no método canguru. Esc. Anna Nery. 2019;23(3):e20180370. https:// doi.org/10.1590/2177-9465-ean-2018-0370

16. Mesquita DS, Naka KS, Kawamura APS, Schmidt AS. Acolhimento de Enfermagem na Unidade de Terapia Intensiva (UTI) neonatal segundo binômio pais-filhos: estudo de revisão integrativa da literatura. REAS. 2019;11(13):e980. https://doi. org/10.25248/reas.e980.2019
17. Reichert APS, Lins RNP, Collet N. Humanização do Cuidado da UTI Neonatal. Rev. Eletr. Enferm. [Internet]. 2009;9(1):200-13. Disponível em: https://www.revistas.ufg.br/fen/article/view/7148

18. Soares NC, Bernardino MPL, Zani AV. Inserção do pai nos cuidados ao filho prematuro hospitalizado: Percepção da equipe multiprofissional. Rev. paul. Pediatr. 2019; 37(3):283-90. https:// doi.org/10.1590/1984-0462/;2019;37;3;00014

19. Holanda SM, Castro RCMB, Aquin PS, Pinheiro AKB, Lopes LG, Martins ES. Influência da participação do companheiro no pré-natal: Satisfação de primíparas quanto ao apoio no parto. Texto contexto - enferm. 2018;27(2):e3800016. https://doi. org/10.1590/0104-070720180003800016

20. Matos MG, Magalhães AS, Feres-Carneiro T, Machado RN. Construindo o Vínculo Pai-Bebê: A Experiência dos Pais. Psico-USF. 2017;22(2):261-71. https://doi.org/10.1590/1413$\underline{82712017220206}$

21. Rocha AM, Chow-Castillo. Os Benefícios do Método Mãe Canguru na UTI Neonatal. Educandi \& Civitas [Internet]. 2020;3(1). Disponível em: http://162.241.180.121/ educandiecivitas/index. php/educandiecivitas/article/view/34/17 